The INL is a

U.S. Department of Energy

National Laboratory

operated by

Battelle Energy Alliance

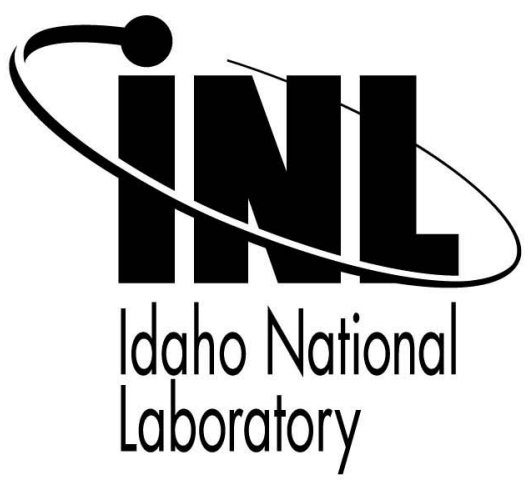

\title{
Design of Wire-Wrapped Rod Bundle Matched Index-of-Refraction Experiments
}

\section{ICONE 16}

\author{
Glenn E. McCreery \\ Hugh M. Mcllroy, Jr. \\ Kurt D. Hamman \\ Hongbin Zhang
}

May 2008

This is a preprint of a paper intended for publication in a journal or proceedings. Since changes may be made before publication, this preprint should not be cited or reproduced without permission of the author. This document was prepared as an account of work sponsored by an agency of the United States Government. Neither the United States Government nor any agency thereof, or any of their employees, makes any warranty, expressed or implied, or assumes any legal liability or responsibility for any third party's use, or the results of such use, of any information, apparatus, product or process disclosed in this report, or represents that its use by such third party would not infringe privately owned rights. The views expressed in this paper are not necessarily those of the United States Government or the sponsoring agency. 


\section{ICONE16-48585}

\section{DESIGN OF WIRE-WRAPPED ROD BUNDLE MATCHED INDEX-OF-REFRACTION EXPERIMENTS}

\author{
Glenn E. McCreery \\ Idaho National Laboratory \\ Idaho Falls, Idaho 83415-3870 \\ Glenn.McCreery@inl.gov
}

\author{
Kurt D. Hamman \\ Idaho National Laboratory \\ Idaho Falls, Idaho 83415-3840 \\ Kurt.Hamman@inl.gov
}

\author{
Hugh M. Mcllroy Jr. \\ Idaho National Laboratory \\ Idaho Falls, Idaho 83415-3870 \\ Hugh.Mcilroy@inl.gov \\ Hongbin Zhang \\ Idaho National Laboratory \\ Idaho Falls, Idaho 83415-3870 \\ Hongbin.Zhang@inl.gov
}

\section{ABSTRACT}

Experiments will be conducted in the Idaho National Laboratory (INL) Matched Index-of-Refraction (MIR) Flow Facility [1] to characterize the three-dimensional velocity and turbulence fields in a wire-wrapped rod bundle typically employed in liquid-metal cooled fast reactors and to provide benchmark data for computer code validation. Sodium cooled fast reactors are under consideration for use in the U.S. Department of Energy (DOE) Global Nuclear Energy Partnership (GNEP) program. The experiment model will be constructed of quartz components and the working fluid will be mineral oil. Accurate temperature control (to within $\pm 0.05^{\circ} \mathrm{C}$ ) matches the index-of-refraction of mineral oil with that of quartz and renders the model transparent to the wavelength of laser light employed for optical measurements. The model will be a scaled 7-pin rod bundle enclosed in a hexagonal canister. Flow field measurements will be obtained with a LaVision 3-D particle image velocimeter (PIV) and complimented by nearwall velocity measurements obtained from a 2-D laser Doppler velocimeter (LDV). These measurements will be used as benchmark data for computational fluid dynamics (CFD) validation. The rod bundle model dimensions will be scaled up from the typical dimensions of a fast reactor fuel assembly to provide the maximum Reynolds number achievable in the MIR flow loop. A range of flows from laminar to fully-turbulent will be available with a maximum Reynolds number, based on bundle hydraulic diameter, of approximately 22,000. The fuel pins will be simulated by $85 \mathrm{~mm}$ diameter quartz tubes (closed on the inlet ends) and the wire-wrap will be simulated by 25 $\mathrm{mm}$ diameter quartz rods. The canister walls will be constructed from quartz plates. The model will be approximately $2.13 \mathrm{~m}$ in length. Bundle pressure losses will also be measured and the data recorded for code comparisons. The experiment design and preliminary CFD calculations, which will be used to provide qualitative hydrodynamic information, are presented in this paper.

\section{INTRODUCTION}

Advanced computer modeling and simulation tools and protocols will be heavily relied on for a wide variety of system studies, engineering design activities, and other aspects of the DOE Global Nuclear Energy Partnership (GNEP). The goal is for all modeling and simulation tools to be demonstrated accurate and reliable, through a formal Verification and Validation $(\mathrm{V} \& \mathrm{~V})$ process, especially where such tools are to be used to establish safety margins and support regulatory compliance. Furthermore, modeling and simulation will minimize expensive prototype testing. Recent literature [e.g., 2,3 , and 4], suggests fundamental methodologies that should be used by experimentalists and CFD practitioners in order to 
ensure that experimental and numerical data meet the standards required for a "benchmark" database. Even for well conducted laboratory and numerical experiments, inconsistent $\mathrm{V} \& \mathrm{~V}$ methodologies and uncertainty quantification, missing experimental details such as geometrical definition, data collection and reduction procedures, and manufacturing tolerances have resulted in a lack of high fidelity data for validation of numerical codes. The validation experiment design described in this paper incorporates the key points stressed in the literature [4], such as, (1), the validation experiment should be jointly designed by experimentalists and CFD practitioners working closely together, (2), the experiment should be designed to capture the essential flow physics, including all relevant physical modeling data and initial and boundary conditions required by the code, (3), an uncertainty analysis should be employed that delineates and quantifies systematic and random error sources by type, and, (4), a hierarchy of experimental measurements of increasing difficulty should be performed.

The experiments to be performed in the facility described in this paper will provide the first step for providing detailed velocity and turbulence benchmark data for fast reactor core flow without the complications of heat transfer. Although there have been many fast reactor core thermal hydraulic experiments conducted in the past, these experiments will be the first that are capable of measuring velocity and turbulence distributions within interior core channels of a wire-wrapped bundle in fine detail. Detailed velocity and turbulence data are necessary for validation of CFD simulations, and especially for the turbulence models employed in these simulations.

\section{MATCHED INDEX-OF-REFRACTION (MIR) FACILITY}

Velocity field measurements will be obtained in the MIR closed-loop flow system located at INL in Idaho Falls, Idaho (see Figure 1). Useful optical flow measurements in a rod bundle would be impractical without refractive-indexmatching. The benefit of the MIR technique is that it permits optical measurements to determine flow characteristics in passages and around objects to be obtained without locating a disturbing transducer in the flow field and without distortion of the optical paths. The innovative advantage of the INL MIR system is its large size, leading to improved spatial and temporal resolution compared to others. The system consists of a stainless steel closed flow loop with a three-chamber polycarbonate and glass test section. The facility operates with light mineral oil as the working fluid.

The working fluid is circulated around the primary flow loop (clockwise in Figure 1) by a 75-hp variable speed axial pump that can provide a maximum volumetric flow rate of approximately $0.6 \mathrm{~m}^{3} / \mathrm{sec}$ of mineral oil. This maximum volumetric flow rate corresponds to a maximum inlet velocity to the test section of approximately $1.7 \mathrm{~m} / \mathrm{sec}$. The test section includes three chambers that are constructed of $3.8 \mathrm{~cm}$ thick polycarbonate supported by a stainless steel framework. Each chamber is fitted with a removable lid. The test section inside dimension is $0.61 \mathrm{~m}$ square and it is $2.44 \mathrm{~m}$ long. Each chamber of the test section is equipped with glass window inserts in the side panels to accommodate high quality optical measurements. The entire facility can be supported on pneumatic vibration isolators.

The working fluid temperature is maintained with a temperature control loop as shown in the lower right corner of Figure 1. This loop extracts approximately $300 \mathrm{~L} / \mathrm{min}$ of mineral oil from the primary flow loop and pumps the fluid through a glycol-cooled heat exchanger and a $10 \mathrm{~kW}$ DC heater for temperature control. The fluid is then filtered and reinjected into the primary flow loop. The temperature control system can maintain the fluid temperature in the test section to within $\pm 0.05{ }^{0} \mathrm{C}$ of the specified index-matching temperature. (The index-matching temperature for the $532 \mathrm{~nm} \mathrm{Nd-Yag}$ laser wavelength used for PIV is $23.3{ }^{\circ} \mathrm{C}$ and the index matching temperatures for the $488 \mathrm{~nm}$ and $514.5 \mathrm{~nm}$ wavelengths for the argon-ion laser used for $\mathrm{LDV}$ are $23.7{ }^{0} \mathrm{C}$ and $24.1{ }^{0} \mathrm{C}$, respectively). An auxiliary flow loop shown in the upper left corner of Figure 1, with a similar temperature control mechanism, is used to provide fluid for models/experiments that require additional flow. As in the primary temperature control loop, the mineral oil is cooled and reheated and then returned to the auxiliary flow loop.

\section{INSTRUMENTATION}

Velocity field measurements will be obtained with a 3-D Particle Image Velocimeter (PIV) from LaVision, Inc ${ }^{*}$. The 3D PIV system consists of two ImagePro Plus digital CCD cameras and a double-pulsed Nd-YAG laser. The system is controlled with DaVis 7.1 software in a LaVision dualprocessor Programmable Timing Unit (PTU). The PIV system cameras are mounted on a 3-dimensional traverse system that is controlled by three separate electric stepping motors. The cameras can be positioned and re-positioned to within 2 micron accuracy using linear stages and digital readouts. The laser position is also controlled with an electric stepping motor. The laser can be positioned and re-positioned to within 5 micron accuracy with an optical linear stage and digital readout.

A two-component, TSI* fiberoptic-based LDV will be used for near wall velocity measurements. The LDV permits finer resolution of velocity and turbulence quantities within it's approximately 10 micron by 100 micron measurement volume than is obtainable using PIV. This fine resolution is necessary for characterizing boundary layer flows.

\footnotetext{
References herein to any specific commercial product, process, or service by trade name, trademark, manufacturer, or otherwise, does not necessarily constitute or imply its endorsement, recommendation, or favoring by the U.S. Government, any agency thereof, or any company affiliated with the Idaho National Laboratory.
} 
The 3-D PIV system that is presently installed on the MIR Facility is shown in Figure 2. The two CCD cameras shown in the figure can be mounted in various configurations designed to support specific model geometries. Additionally, the double-pulsed laser shown beneath the test section in the figure can also be mounted to support specific experimental requirements. Calibration for internal flow experiments, such as these, is performed using a calibration plate positioned outside the apparatus (but within the main MIR test section). The cameras are then translated inward to the desired measurement location.

\section{ROD BUNDLE APPARATUS DESIGN}

The design focuses on a seven rod bundle since a three rod bundle was not expected to provide sufficient subchannel cross-flow and mixing. Furthermore calculations show that flow in a 19 rod bundle model, the next larger triangular pitch symmetrical bundle that fits in a hexagonal duct, would not provide sufficiently high Reynolds numbers for fully turbulent flow.

The design relies on a Mathcad (MathSoft, Inc.) computer program that was developed to calculate flow, pressure loss, pumping power, and temperature increase in physical models placed in the MIR loop test section with flow provided by either the main loop flow or the auxiliary loop. The program has provided sufficiently accurate calculation for the design of previous MIR flow loop experiments, including one previous rod-bundle experiment [5]. For example, a previous rod bundle experiment which consisted of a two-rod bundle with grid spacers and enclosed in a rectangular cross-section duct which was representative of a supercritical water reactor core design. Pressure losses for the wire-wrapped rod bundle were calculated using the Rehme (1972) correlation [6]. The Novendstern (1972) correlation [7], which formulates overall bundle loss coefficient as a function of Reynolds number, rod pitch, and wire wrap pitch, was also used for comparison and gave similar, although approximately $10 \%$ to $15 \%$ higher bundle pressure losses.

Two experiment design approaches were investigated. The first approach positioned the rod bundle in the test section; funnel main-loop fluid flowed through and around the model, as shown in Figure 3. The second approach is to use the auxiliary flow loop and auxiliary temperature control loop shown in Figure 1 to provide flow into the model. This approach was chosen because it provides higher Reynolds numbers while providing sufficient length to hydraulic diameter ratio and length to wire-wrap diameter ratio to ensure well developed turbulent flow.

The work of Cheng and Todreas [8], was used to provide insight into the appropriate rod-bundle dimensions required for turbulent flow. The authors generated correlations for flow transitions in wire-wrapped rod bundles using their own and other's data. A Reynolds number transition map, extracted from their article, is shown in Figure 4. Noteworthy is the fact that the laminar to turbulent flow transition occurs over a much larger range of Reynolds numbers, in comparison to internal tube flow, due to the wide range of internal dimensions. Turbulence is reported to first occur in the subchannel region midway between three surrounding rods in a triangular pitch array and to then slowly propagate with increasing Reynolds number to the narrower regions between adjacent rods. The results from the MathCad computer program are displayed in figure 8 .

Table 1 presents the design dimensions and component tolerances of the rod bundle design. The rod bundle will be constructed of commercially available quartz tubes (the fuel rods will be simulated using quartz tubes rather than quartz rods since rods of this large a diameter and sufficient length are not commonly available) and solid quartz rods (the wire-wrap will be simulated by quartz rods).

The maximum achievable Reynolds number in this design is approximately 22,000, which exceeds, by a comfortable margin, the minimum Reynolds number for fully turbulent flow of approximately 17,000 , according to the Cheng and Todreas, 1984, correlation [8] (see Figure 4). The choices of rod pitch/diameter and wire wrap pitch/diameter are chosen to fall within the range of prototypical values listed by Tang et al. [9], although they do not correspond to any one particular prototype. The final choice is a compromise between maximum achievable Reynolds number, rod pitch/diameter, bundle length/hydraulic diameter, and number of wire wraps. The choice is also compatible with PIV camera and MIR test section windows placement and other design constraints. The number of wire wraps may or may not may not be sufficient to provide fully developed flow near the exit. However, since the CFD codes are capable of predicting developing flow, the velocity measurements will provide useful data for CFD validation.

The rod bundle is designed to rotate on-axis in order to permit views from various angles for the PIV cameras. The simulated fuel rods and canister will be approximately $2.13 \mathrm{~m}$ (7 ft.) in length. However, quartz tubes are typically available in lengths of six feet or less, quartz rods in lengths of four feet or less, and quartz plates in lengths of two feet or less (for our required width). Therefore, quartz sections of the channel will be used for the bundle section viewed by the approximately two foot length downstream window of the MIR test section (placed furthest downstream of the bundle entrance to help insure fully-developed flow) and the inlet, since accurate measurements of inlet flow distribution is necessary for code input. The remainder of the channel will be constructed from aluminum plates. The $2.13 \mathrm{~m}$ length quartz tubes and $2.68 \mathrm{~m}$ length of rods (the length required to wrap a tube) will be constructed from two tubes or rods spliced together with smoothed and polished joints. The simulated wire wrap will be constructed by heating a quartz rod to its softening temperature and then wrapping it around a simulated fuel rod and then pinning it in place at the ends to prevent movement. The tolerance buildup of constructing the rod bundle from individual wire-wrapped rods requires manufacture of the 
individual wire wrapped rods first and then, after measuring the over-all dimensions of the bundle, constructing the canister and supporting structure to fit. Careful recordings of as-built dimensions are then required for modeling and simulation purposes.

\section{COMPUTATIONAL FLUID DYNAMICS SIMULATION}

A preliminary CFD simulation was developed in order to provide insight and qualitative information for the design of the wire-wrapped rod-bundle experiment. The simulation process consisted of four phases which included creating a solid-model using commercial CAD software, generating a computational mesh and running the simulation on high performance computers (HPCs) using commercial CFD software, and conducting rudimentary validation studies using empirical correlations published in the literature. Lessons-learned from a previous CFD study of a 19-pin fast reactor assembly, which consisted of 65.5 million elements, were incorporated into the rod-bundle CFD simulation [10].

A computer aided design (CAD) solid model was created using SolidWorks [11], as shown in Figure 5. This solid model was used to create the computational fluid volume shown in Figure 6; the rotation direction of the spacer wire is clockwise when viewed from the rod-bundle outlet. Commercial CAD software was used due to the geometric complexities created by modeling the wire-wrap spacers, making the use of less sophisticated techniques for creating solid models impractical. Furthermore the capability to quickly change rod-bundle dimensions, especially when evaluating modeling tradeoffs, significantly reduces the time required to generate a computational mesh. For example, a solid model with sharp corners could result in a poor quality computational mesh; therefore, several iterations between the solid modeling phase and mesh generation phase could be required in order to obtain a computational mesh of sufficient quality. A specific example of a modeling tradeoff is shown in Figures 7 and 8. Due to the preliminary nature of this study, additional equipment such as assembly support structures was not modeled. Based on previous experience modeling rod-bundles, the desire to minimize geometric modeling uncertainty, and the meshing capabilities of Star-CCM+ [12], the commercial CFD software used for this study, the geometry shown in Figure 8 was modeled in the simulation.

Computational requirements for meshing and running the simulation were significant. Contributing to this was the need to predict the complex fluid flow created by the wire-wraps. In fact, considerable effort was taken to resolve the momentum boundary layer, so as to minimize the need for wall functions and reduce simulation uncertainty (wall functions are typically used in turbulence modeling to reduce computational overhead by not having to resolve the boundary layer). The 3-D fullscale simulation consisted of a 55.7 million hybrid mesh consisting of polyhedral and hexahedral boundary elements; the mesh is shown in Figures 9 and 10. Because the commercial software did not have parallel meshing capabilities and meshing required approximately $30 \mathrm{~GB}$ of memory, the mesh was generated on a SGI Altix 4700 shared memory machine with $256 \mathrm{~GB}$ of memory and $1.5 \mathrm{GHz}$ clock speed. Furthermore, the full-scale problem was simulated on a Dell Power Edge 1950 distributed memory cluster with a $2.66 \mathrm{GHz}$ clock speed. The simulation file size was $22.1 \mathrm{~GB}$ and the simulation memory requirements were approximately $65 \mathrm{~GB}$. Approximately 24 hours was required to generate one computational mesh; simulation time was approximately 3 days.

The following STAR-CCM+ simulation settings were used: 3-D incompressible isothermal flow, SST (Mentor) k- $\omega$ turbulence model with "all $\mathrm{y}+$ wall treatment,", steady-state segregated solver, using second order upwind convection schemes. Material properties for mineral oil at $23.3^{\circ} \mathrm{C}$ (the index-matching temperature used for PIV measurements) were used. A velocity of $5.8 \mathrm{~m} / \mathrm{s}$ was specified at the inlet, and a static pressure of 0 psi was specified at the outlet. Inlet velocity of $5.8 \mathrm{~m} / \mathrm{s}$ was chosen to ensure that turbulent flow would exist within the computational domain; Reynold's number based on hydraulic diameter was 24,800 . The inlet and outlet boundary values for turbulent intensity and turbulent length scale were 0.01 and $0.4 \mathrm{~mm}$ respectively. Turbulent length scale was chosen as $40 \%$ of the expected boundary layer thickness as suggested in Reference 13.

As a first step in validation of the simulation, global pressure results were compared with Rehme's (1972) empirical correlation [6]. Average pressure across the inlet face was computed and used to determine axial pressure drop across the entire bundle. The simulation predicted a pressure drop of 96.2 $\mathrm{Pa} / \mathrm{cm}$, while Rehme's (1972) correlation predicted a pressure drop of $87.6 \mathrm{~Pa} / \mathrm{cm}$. Such close agreement between the simulation and Rehme's correlation is encouraging in that it provides the CFD practitioner with a sense that the global pressure results provided by the simulation are reasonable.

Velocity magnitude information for the rod bundle horizontal mid-plane and outlet is presented in Figures 11 and 12. Maximum velocity in these two planes varies from $8.2 \mathrm{~m} / \mathrm{s}$ to $7.5 \mathrm{~m} / \mathrm{s}$ while the maximum velocity within the computational domain was $9.8 \mathrm{~m} / \mathrm{s}$. Noteworthy is the contour plot of velocity magnitude at the rod-bundle outlet which shows the development of several vortices spawned at the surfaces of the rods indicating the usefulness of wire-wraps in enhancing turbulent mixing. This type of velocity information is useful to the experimentalist in determining appropriate locations to investigate turbulence phenomena. For example, vortices are formed at both the mid-plane and exit planes, yet the vortices at the outlet are more pronounced indicating that the outlet plane would be a better choice for collecting turbulence information. Additional CFD analyses are required to confirm that the flow is fully-developed. For example, the axial length of the assembly could be extended from two to three wire-wrap pitches; and velocity and turbulence information could be compared at several axial locations to confirm fully-developed flow. 
Pressure results are presented in Figures 13 thru 16. These results are beneficial since they provide insight into the pressure distribution on the rod-bundle canister walls; ultimately, this information will help guide placement of pressure sensors. Figures 13 and 14 show static pressure on planes parallel and perpendicular to the longitudinal axis. Noteworthy is the local areas of high and low pressures induced by the wire-wraps. Figures 15 and 16 show dimensionless values of pressure distribution plots along the peripheral of the horizontal mid-plane and the axial canister walls of the rod-bundle which provide qualitative information regarding the distribution of pressure on the rod-bundle exterior. Dimensionless pressure, referred to as "pressure coefficient" in Reference 12, is defined as

$$
C_{p}=\frac{\left(p-p_{r e f}\right)}{\left(0.5 * \rho_{r e f} V_{r e f}^{2}\right)}
$$

Where $P_{r e f}, \rho_{\text {ref }}$, and $V_{\text {ref }}$ represent atmospheric pressure, mineral oil density, and rod-bundle inlet velocity. Specific values are as follows.

$P_{r e f}=101325 \mathrm{~Pa}, \rho_{\text {ref }}=830.9 \mathrm{~kg} / \mathrm{m}^{3}, V_{\text {ref }}=5.8 \mathrm{~m} / \mathrm{s}$

These values were chosen in order to be consistent with parameters readily available to experimentalists in the laboratory.

The horizontal mid-plane peripheral distributions are consistent with those developed by Fernandez and Carajilescov [14]. These plots suggest the need for numerous pressure transducers or one or more traversing pressure probes in order to capture the unique features of the pressure profiles; capturing these features is required in order to produce high fidelity benchmark data.

\section{CONCLUDING REMARKS}

The matched index-of-refraction flow experiments discussed in this paper will provide the first step for providing detailed velocity, pressure, and turbulence benchmark data for fast reactor core flow without the complications of heat transfer. Detailed information of flow parameters is required to validate CFD simulations; especially the turbulence models employed in these simulations. The experiments will be the first to generate velocity, pressure, and turbulence data within interior wire-wrapped rod bundle channels in fine detail. The importance of CFD simulations in designing experiments was demonstrated. Results from the CFD simulation help provide the insight needed to properly design and plan the upcoming experiments.

\section{REFERENCES}

[1] Stoots, C. M., Becker, S, Condie, K.G., Durst, F. and McEligot, D.M., "A Large-Scale Matched-Index-Of Refraction Flow Facility For LDA Studies Of Complex Geometries", Exp. Fluids, 30, pp. 391-398, 2001.
[2] Freitas, C.J., Ghia, U., Celik, I., Roache, P., and Raad, P., "ASME's Quest to Quantify Numerical Uncertainty", AIAA -2003-027, 2003.

[3] Roache, P.J., "Verification and Validation in Computational Science and Engineering", Hermosa, Alburquerque, 1998.

[4] AIAA, "Guide for the Verification and Validation of Computational Fluid Dynamics Simulations," AIAA G077-1998, 1998.

[5] McEligot, D.M., et al., "Advanced Computational Thermal Fluid Physics (CTFP) And Its Assessment For Light Water Reactors And Supercritical Reactors", INEEL/EXT-0301215, December, 2003.

[6] Rehme, K., "Pressure Drop Correlations for Fuel Element Spacers," Nuclear Technology, vol. 17 pp. 15-23, 1972.

[7] Novendstern, E.H., "Turbulent Flow Pressure Drop Model For Fuel Rod Assemblies Utilizing A Helical Wire Wrap Spacer System”, Nuc. Eng. Design, vol. 22, pp. 19-27, 1972.

[8] Cheng, S., and Todreas, N.E., "Hydrodynamic Models And Correlations For Bare And Wire-Wrapped Hexagonal Rod Bundles-Bundle Friction Factors, Subchannel Friction Factors And Mixing Parameters", Nuc. Engr. And Design, vol. 92, pp. 227-251, 1986.

[9] Tang, Y.S., Coffield, Jr., R.D., and Markley, R.A., "Thermal Analysis Of Liquid Metal Fast Breeder Reactors", American Nuclear Society, 1978.

[10] Hamman, K.D and Berry, R.A, "CFD Modeling Process (19-Pin Fast Reactor Assembly)", Idaho National Laboratory document, INL/MIS-07-13499, 2007.

[11] SolidWorks, see www.solidworks.com

[12] STAR-CCM+, see www.cd-adapco.com

[13]Fluent 6.3 User Guide, see www.fluent.com

[14]Fernandez, E.F. and Carajilescov, P., "Static pressure and wall shear stress distributions in air flow in a seven wirewrapped rod bundle," J. Brazilian Society of Mechanical Sciences, 22, 2000. 


\section{TABLE}

Table 1. Rod bundle nominal design dimensions and tolerances.

\begin{tabular}{ll}
\hline Rod Diameter & $85 \mathrm{~mm} \pm 1.5 \mathrm{~mm}$ \\
Rod length & $2.13 \mathrm{~m} \pm 3 \mathrm{~mm}$ \\
Rod Pitch/Diameter & $1.294 \pm 0.025$ \\
Wire wrap diameter & $25 \mathrm{~mm} \pm 0.5 \mathrm{~mm}$ \\
Wire wrap Pitch/Rod Diameter & 12.55 \\
Length/Hydraulic Diameter & 38.76 \\
$\begin{array}{l}\text { Number of wire wraps } \\
\text { (on 2.13 m length rod) }\end{array}$ & 2 \\
\hline
\end{tabular}

\section{FIGURES}

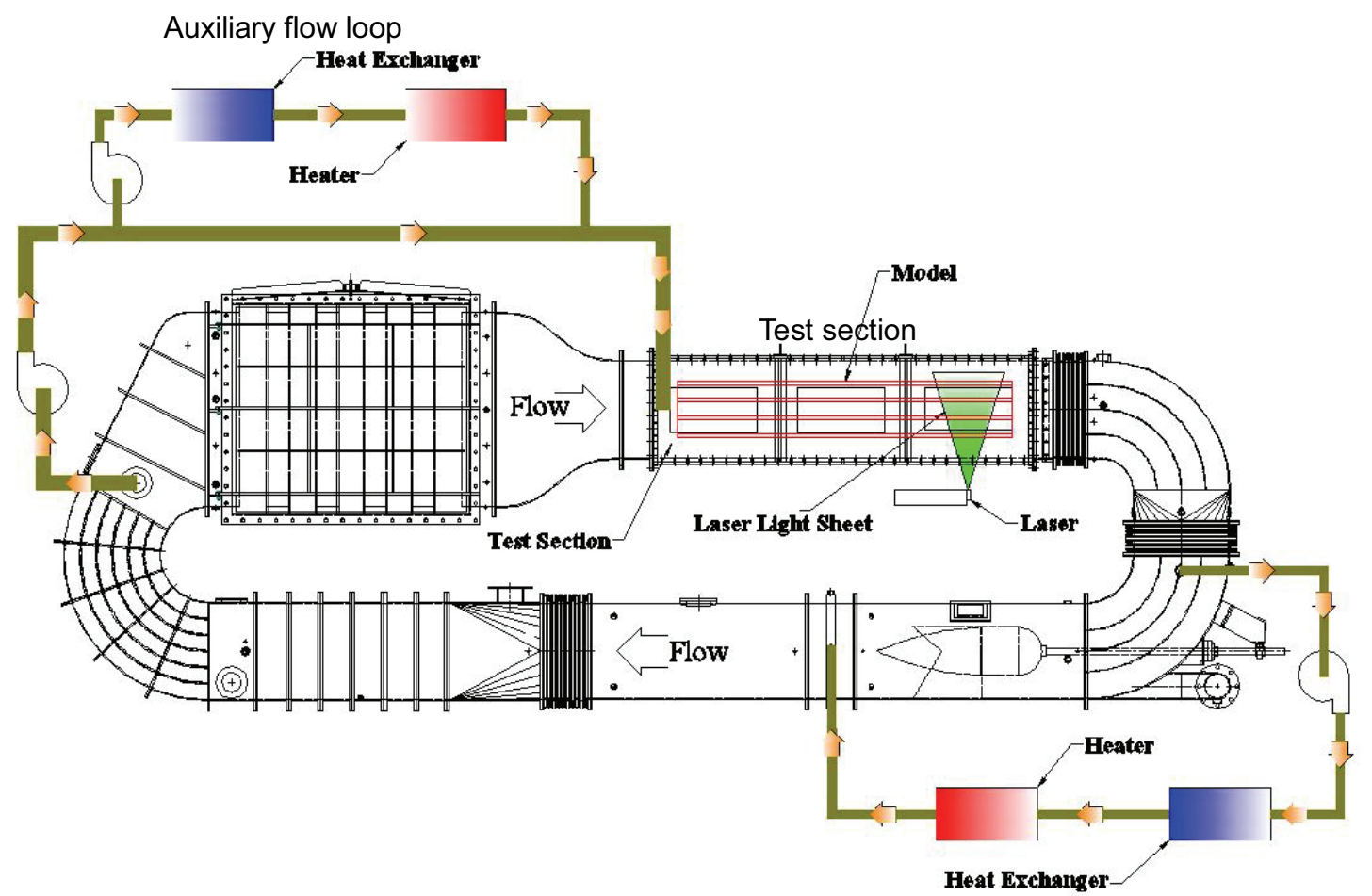

Figure 1. MIR facility closed loop flow system. 


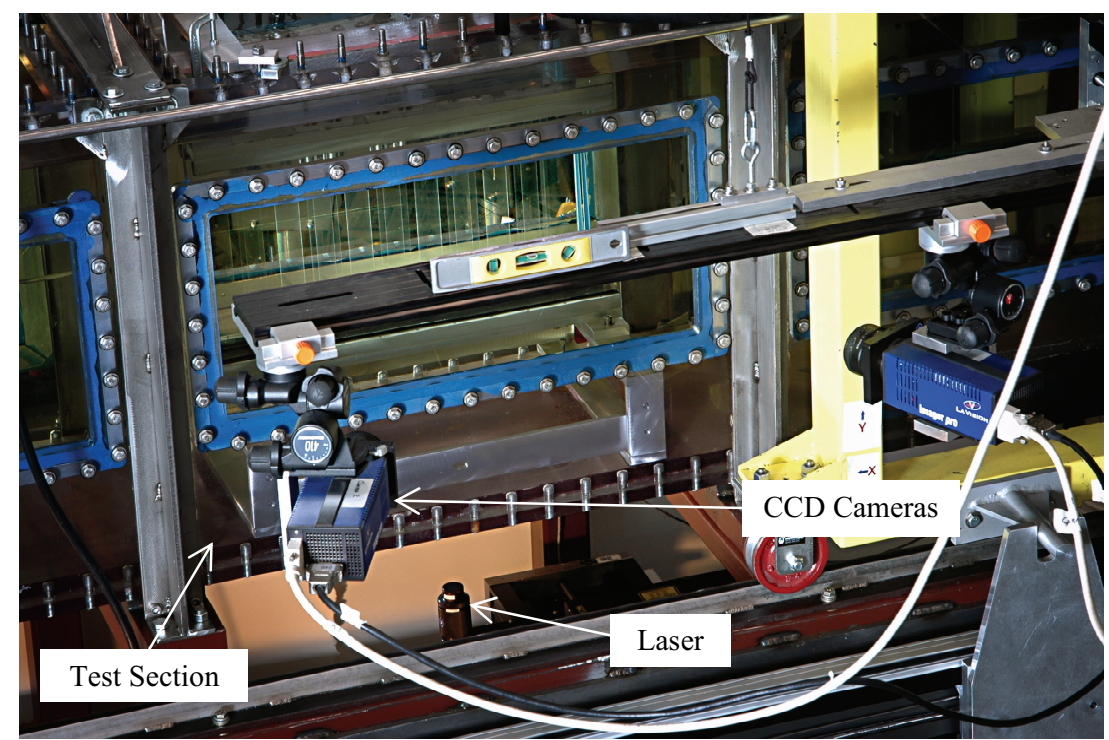

Figure 2. 3-D PIV system installed on MIR facility closed loop flow system.

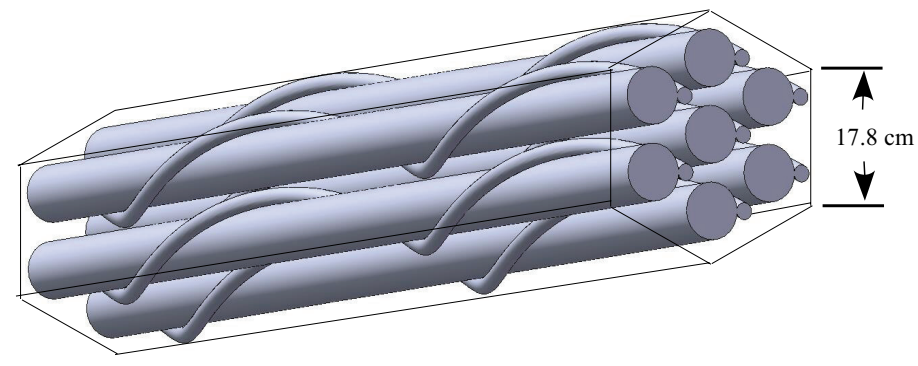

Rod bundle and canister constructed of quartz components

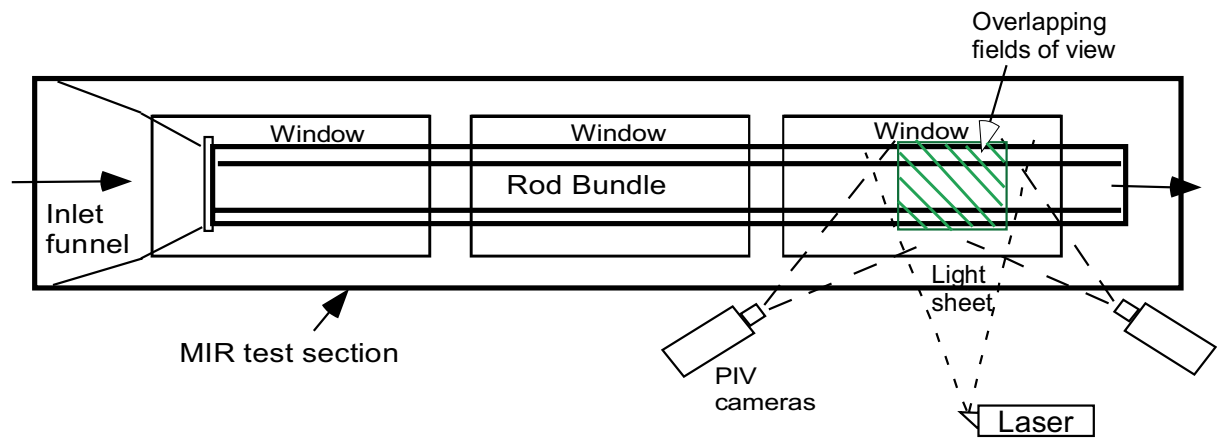

Side View

Figure 3. 7-rod bundle and positioning in main MIR flow loop test section. Main MIR flow is funneled through bundle. PIV measurements are obtained through the furthest downstream test section window. 


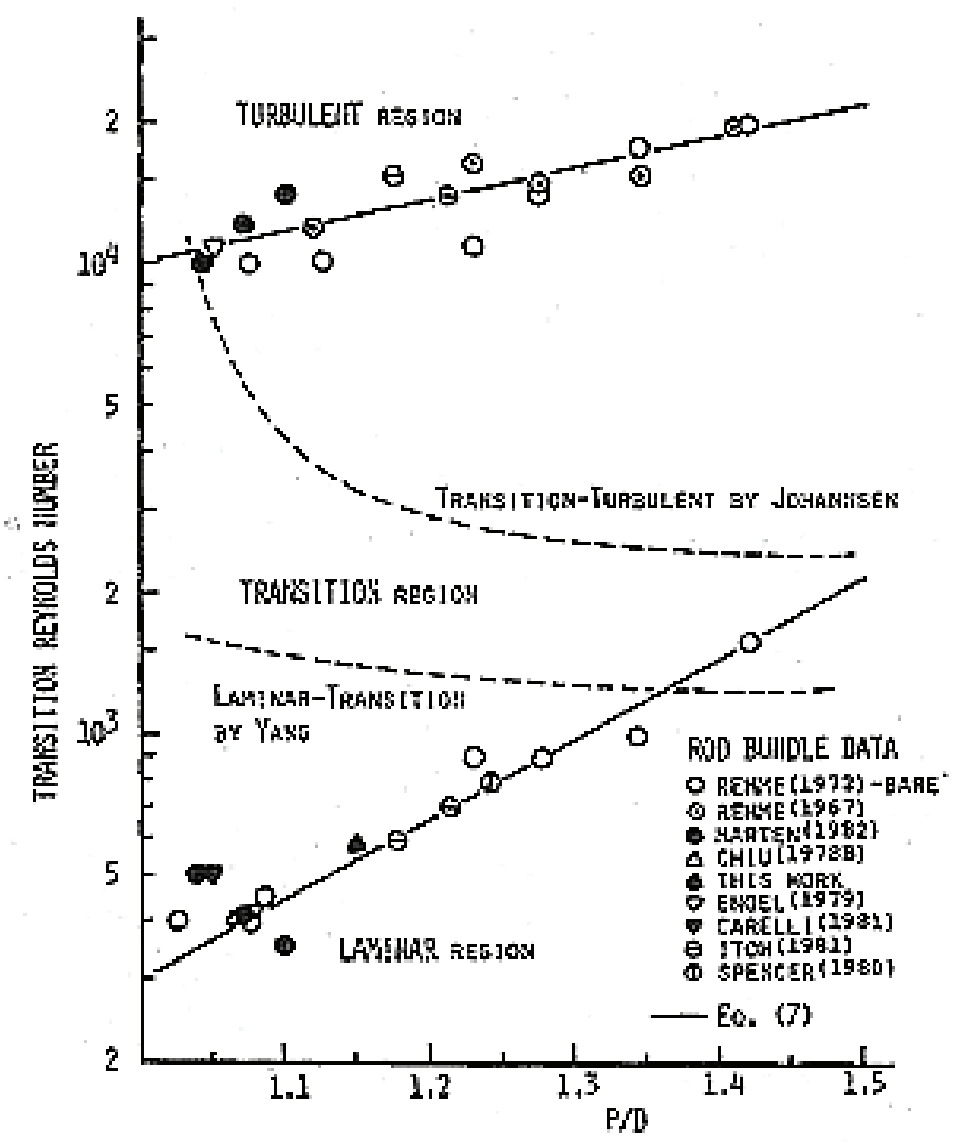

Fi3. 2. Ditz and propoed corretations for the iransillos Rezrolds number.

Figure 4. Reynolds number transition map for flow in wire-wrapped rod bundle. From Cheng and Todreas, 1984.

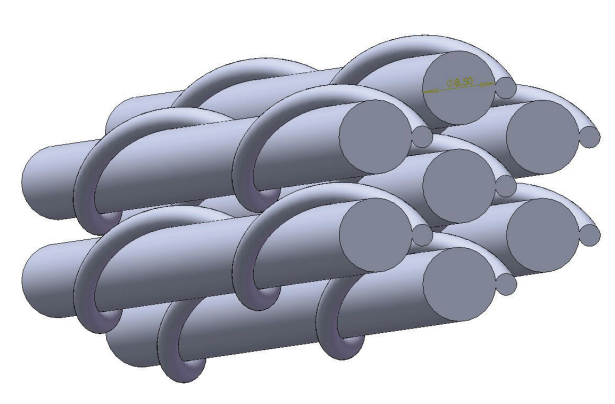

Figure 5. 7-Pin bundle CAD solid model.

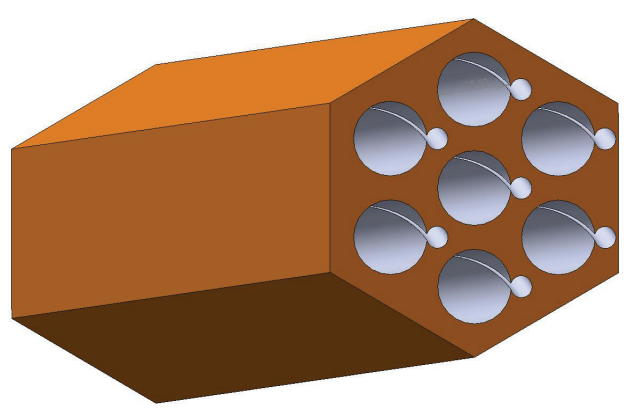

Figure 6. 7-Pin bundle CAD fluid model, showing outlet face. 


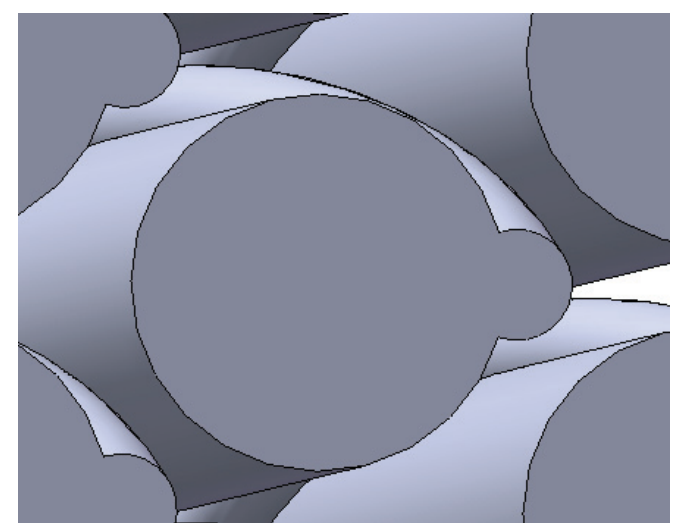

Figure 7. Geometric model A.

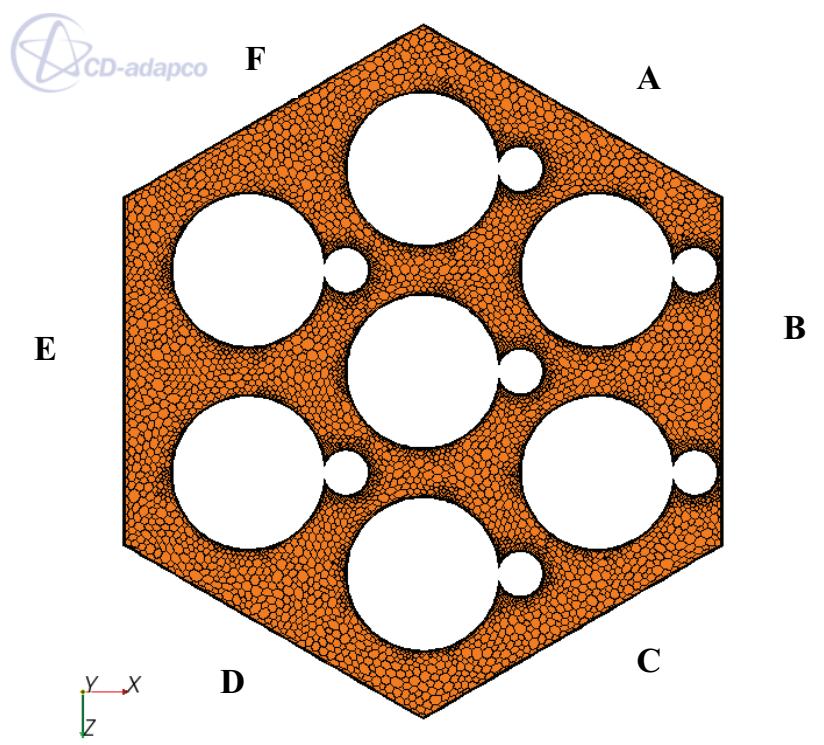

Figure 9. Outlet boundary mesh and canister wall (flat) identification.

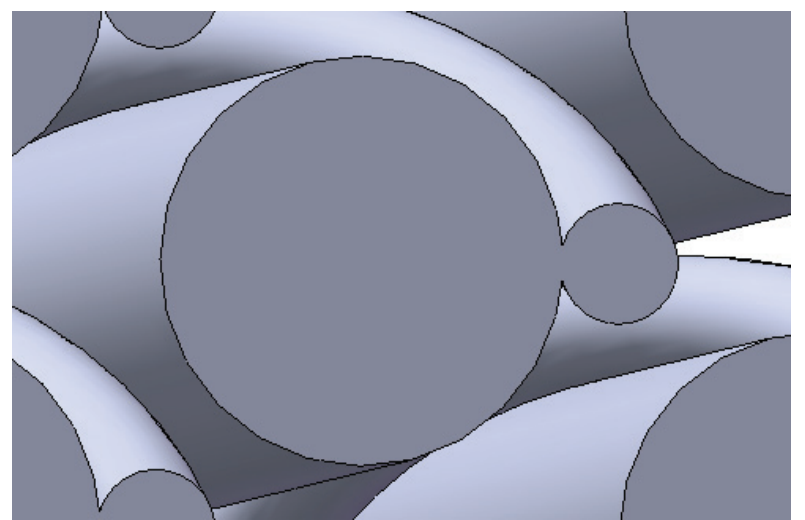

Figure 8. Geometric model B.

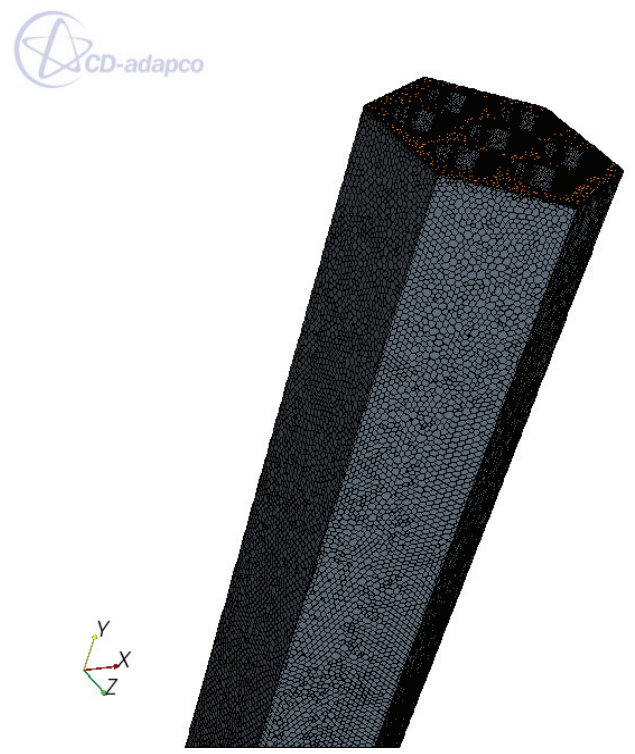

Figure 10. Exterior boundary mesh. 


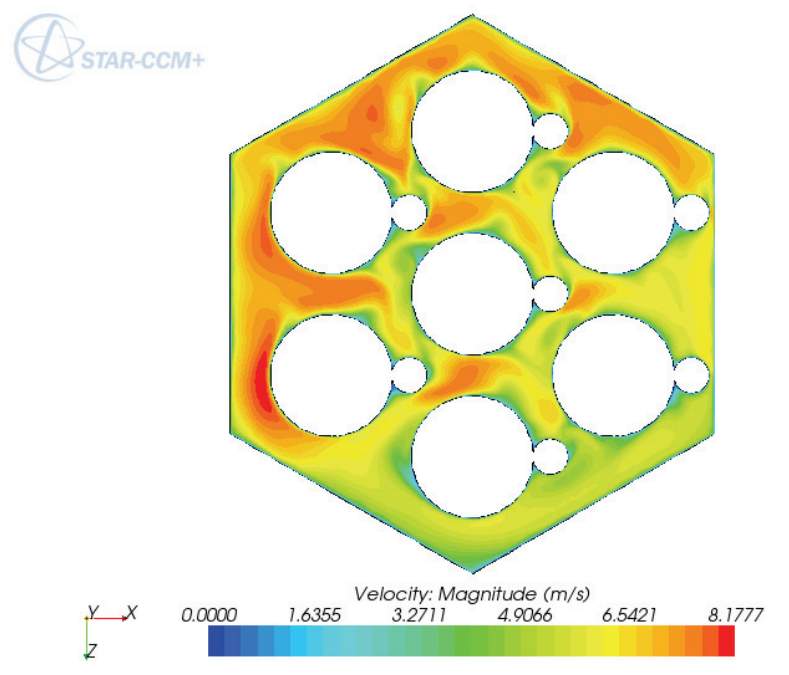

Figure 11. Mid-plane velocity magnitude distribution.

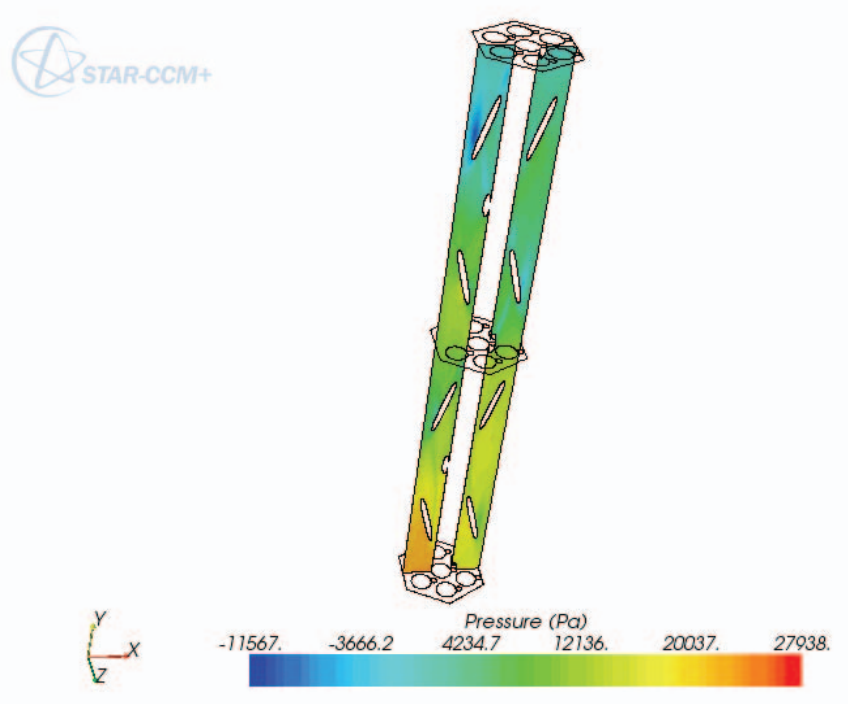

Figure 13. Axial plane static pressure distribution.

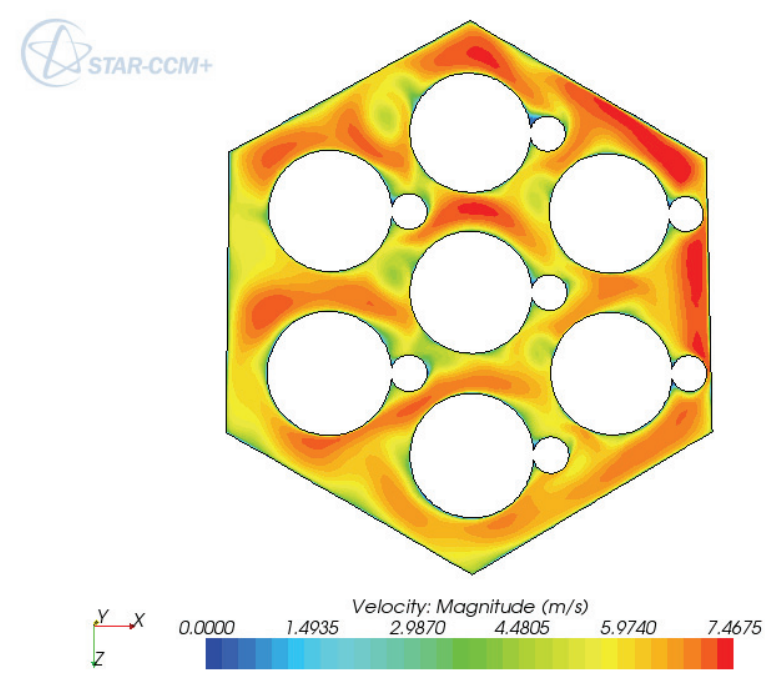

Figure 12. Outlet velocity magnitude distribution.

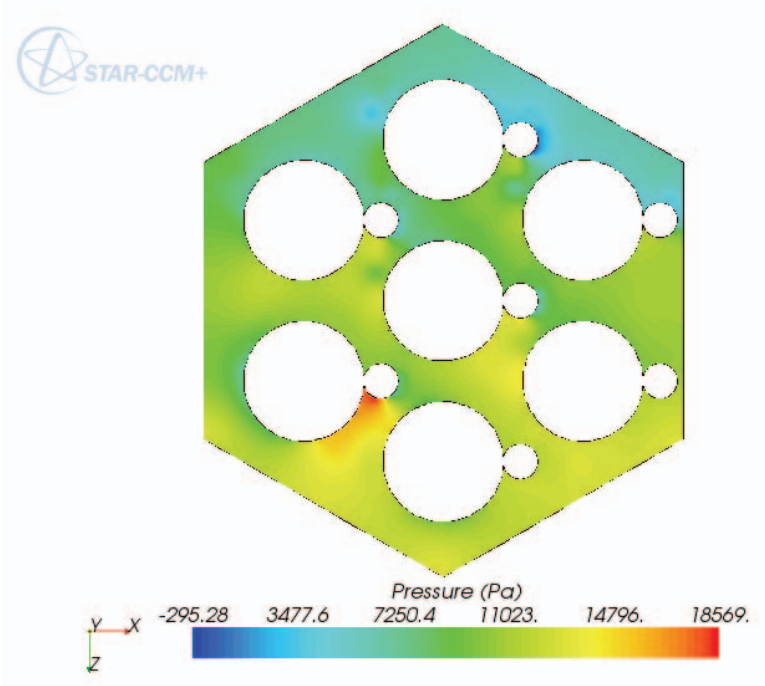

Figure 14. Mid-plane static pressure distribution. 


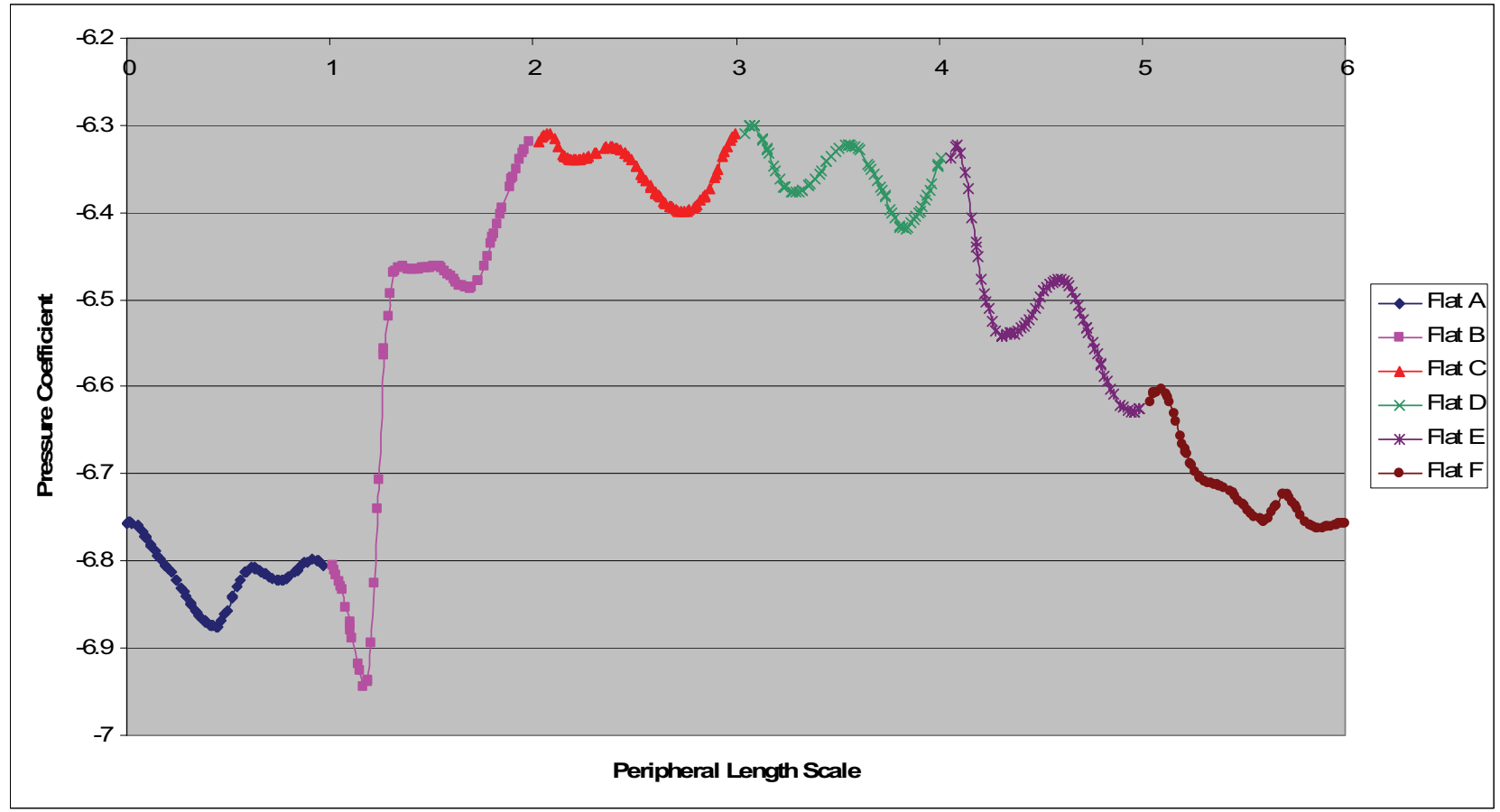

Figure 15. Mid-plane hexagonal duct wall (flat) peripheral static pressure distribution.

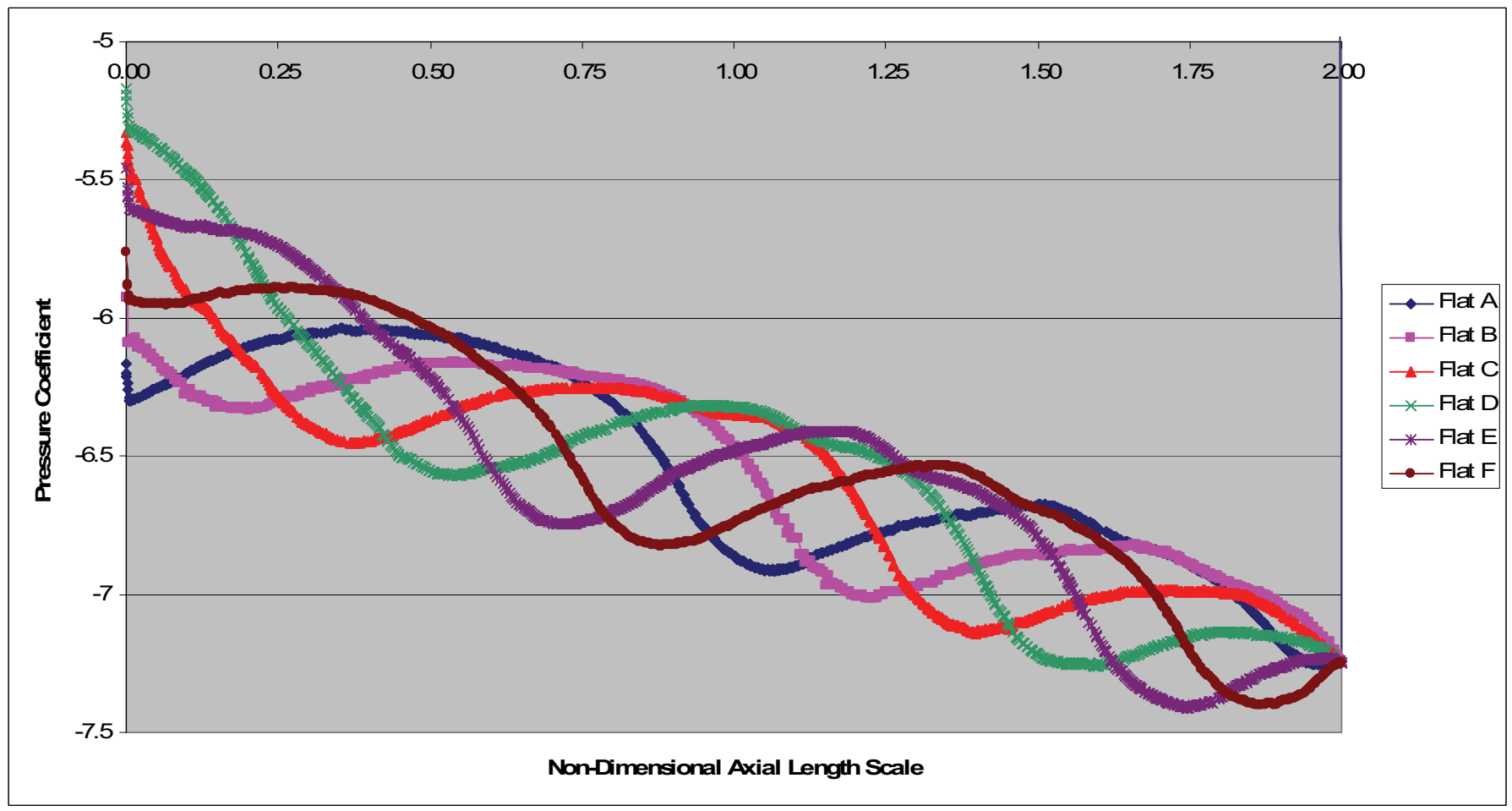

Figure 16. Hexagonal duct wall axial static pressure distribution. 